\title{
Study on Management of Small and Medium Sized Electronic Commerce Enterprises
}

\author{
Yaping Qian ${ }^{1, ~ a}$, Qiyuan Cui ${ }^{2, b}$ RunjieShen ${ }^{3, c}$ \\ ${ }^{1}$ Foreign Language College, Hangzhou Normal University Hangzhou ,Zhejiang and College of \\ Economic and Management, Tongji University, Shanghai, China \\ ${ }^{2}$ College of Economic and Management, Tongji University, Shanghai, China \\ ${ }^{3}$ College of Electronic and Information Engineering, Tongji University, Shanghai, China \\ a1152771465@qq.com, bcqy@tongji.edu.cn, c'shenrunjie@tongjing.edu.cn
}

Keywords: Electronic Commerce; SMEE; Management

\begin{abstract}
The role of small and medium-sized enterprises(SMEs)can not be replacedfor their importance in economic development.However, they face many difficulties during the economic crisis. One of the effective ways to solve the problem as soon as possible is to carry out E-commerce. This assay discusses the problems and solutions in small and medium sized electronic commerce enterprises (SMEEs )in China.
\end{abstract}

\section{Introduction}

E-commerce refers to a business formal in which all kinds of entities make use of internet technology and network communication means to trade goods or services in order to improve the efficiency of the commercial operations, and provide related services.E-commerce plays an important role in the informationization of the national economy and is an important channel of the development of SMEs. E-commerce helps enterprises to adjust the market, inspires the processing of brand innovation, and guides SMEs to realize the information managementand so on. A report called The Social And Economic Impact of E-commerce Services shows that in a trade atrophy and consumer tightening environment, E-commerce in China expands rapidly, which actually goes against the market tendency.During the next two years, the growth rate is at a height of 28\%, making Chinese economy the most dazzling bright spot in the future. Therefore, the use of E-commerce will become the inevitable choice for SMEs.

\section{Analysis on the current situation of business management in SMEEs}

With the change of people's consumption habits--shopping from entity shop to online ones, small and medium-sized e-commerce enterprises arespringing up. Their development speed far exceeds the speed of management level, which makes chaos in the internal management and SME managers often feel at loss. Employees also can not find a sense of belonging and steady. As a result, job hopping is excessive and frequent. When the new career of the employees learn e-commerce shop customer service, shop promotion and other skills, they think of ways to jump to a higher wage e-commerce company The urgent affairs of small and medium-sized electronic commerce enterprise is to make a suitable system to strengthen the internal management, keep the enterprise staff and stabilize the production. 


\section{Management Strategy for SMEEs}

SMEEs Should Take the Initiative to Adapt to the Environment. With the dramatic changes in the environment, it is hard for enterprises to rely on the past successful experience to cope with the challenges of the future. Business managers need to tap the market space for the neglect of others. SMEEs should use their own advantages to identify themselves in the competitive market.

Enterprises Should Change the Management Concept and Business Strategy. SMEE leadership should not only consider the development of their business, at the same time, more attention should be paid on how to adapt to the needs of economic and social development to build a new enterprise. A lot of enterprises dependent too much on foreign orders and foreign markets before, nevertheless, they have to consider adjusting the internal business portfolio and the development of coping strategies[1].

Enterprises Should Improve Operational Efficiency and Change the Mode of Production. SMEEs generally pay great attention to the sale, but little to production. A lot of e-commerce enterprises simply do not have the production factory. They often look for one or several suitable OEM factory.Common problems are: Quality and cost controlare not in place, added value of products is relatively low, enterprise organization structure is not very complete, business and management process is not standard and so on. These are problems need to be resolved in the course of the operation of the enterprise. It is necessary to carry out science and technology transformation and innovation.

SMEEs Should Accelerate Technological Progress and Structural Adjustment. Local government encourages SMEEsfrom tax, loans, venture capital and the transformation of scientific and technological achievements[2]. SMEEs, scattered in factories, cities and remote areas, usually have a characteristic that they are good at studying certain technologies or a few product. Product design, production tools, quality assurance and production efficiency can be achieved at a high level. SMEEsshould seize the opportunity to actively cooperate with the government,universities or scientific research institutions.

SMEEs Should Fully Realize the Planning and Construction of Business Management. Management system and enterprise culture should be improved. More attention can be paid to enterprise's overall image and the overall competitive advantagethrough strengthening the strategic management, management system, organization structure, enterprise brand construction to form a distinct concept of the enterprise and unique corporate culture[2], so that employees have a strong sense of belonging and professionalism. It's better the implementation of the management system start from the leaders, who has a pivotal role in the behavior of others to follow.

Adhere to large enterprises. Choose the place where logistics industry is developed as the place where the enterprise is located or where the warehouse is located. Strengthen cooperation with large scale e-commerce industry or large traditional manufacturing enterprises. SMEEs can use the platform and influence of the large business enterprise such as Taobao, Jingdong Mall to survive and develop[3]; cooperation with large traditional production enterprises can ensure the stability and reliability of product quality and supply continuity .

Strengthen the construction of honesty. The credit construction of SMEEs must be strengthened. Good faith maintains confidence and good creditto win customers, large enterprises and banks to support and trust, so that the enterprise is able to survive and develop.

\section{Problems Should Be Paid Attention to in the Application of SMEEs}

To develop electronic commerce is system engineering. Compared with large enterprises, SMESare 
weaker in human resource, financial, material and information technology [4]. Therefore, some problems need to attract enough attention.

The Way Of Developing E-Commerce In Different Enterprises Is Different. From using Internet browsing, collection, dissemination of information to set up enterprise's websites, build information platform, the implementation of online purchasing, then to establish the industry joint purchasing platform, improve their own supply chain management system etc. [5], the implementation of SMEE is gradually put in place. In the initial stage of e-commerce, it can be considered comprehensively from the aspects of products, capital, technology and business development.Some enterprises may need to use electronic commercein customer management and services, and some may in corporate image, product propaganda, circulation of materials, production management or other aspects. So SMEEs can use their own advantages for the specific implementation of e-commerce construction.

Implementation of SMEEs Can Not Be Achieved Overnight. SMEEs' own business and resource constraints determines they should be implemented step by step to strengthen basic management, promote enterprise standardization, collate basic data, improve business processes, and even make the necessary institutional changeto provide a good environment for enterprise information, and then, establishauthorityof the decision-making and management agencies to unify planning. At last, start from the current capacity of the enterprise, implementation of E-commerce should be neither greedy to invest blindly nor hesitate.

\section{Conclusion}

The existence of large scales of SMEs isa universal law of economic development, especially with the further refinement of the professional division of labor, and the advent of knowledge economy and information age. SMEs, "small and professional", "small and live", "small and special", play important rolein national economy. Meanwhile, there is a lack of talent, backward technical equipment, lack of financial support and other issues. With the market competition environment becomes increasingly fierce, their anti risk ability get weaker. However,E-commerce just make full use of their advantages while eliminating the problem of information asymmetry. So E-commerce will play a more and more important role in SMEs business. Due to the outstanding application requirements from SMEEs, policy to SMEEs tilt.And along with an increasingly rich products and foreign investment, E-commerce application of SMEs in China has ushered the favorable opportunity of high speed development.

\section{References}

[1] Meng Fanjin, E - commerce - the fast lane of development of small and medium sized enterprises, [J]. China market. (2008) 23.

[2] Wu Cong,Small and medium-sized enterprise e-commerce application problems and Countermeasures, [J]. modern commerce industry.( 2009 )8.

[3] Shen Fengchi, Study on market development trend of the application of electronic commerce in the small and medium-sized enterprise modernization, [J].( 2008 )21.

[4] Fang Chengmin, Li Yuqing, Study on the application of e-commerce in small and medium sized enterprises, [J]. (2007) 5.

[5] Jingyang, Gu Shikui,E-commerce development of small and medium-sized enterprises of China trading, [J].(2011) 24. 